\title{
The effect of beta1-adrenergic receptor gene polymorphism on prolongation of corrected QT interval during endotracheal intubation under sevoflurane anesthesia
}

\author{
Kyungsoo Park ${ }^{1}$, Seong Bok Jang ${ }^{1}$, Tae Dong Kweon ${ }^{2}$, Jun Ho Kim³ , and Dong Woo Han ${ }^{2}$ \\ Departments of ${ }^{1}$ Pharmacology, ${ }^{2}$ Anesthesiology and Pain Medicine and Anesthesia and Pain Research Institute, ${ }^{3}$ Anesthesiology \\ and Pain Medicine, Yonsei University College of Medicine, Seoul, Korea
}

Background: The hemodynamic responses to endotracheal intubation are associated with sympathoadrenal activity. Polymorphisms in the betal-adrenergic receptor $\left(\beta_{1} A R\right)$ gene can alter the pathophysiology of specific diseases. The aim of this study is to investigate whether the Ser49Gly and Arg389Gly polymorphism of the $\beta_{1} A R$ gene have different cardiovascular responses during endotracheal intubation under sevoflurane anesthesia.

Methods: Ninety-one healthy patients undergoing general anesthesia were enrolled. Patients underwent slow inhalation induction of anesthesia using sevoflurane in $100 \%$ oxygen. Vecuronium $0.15 \mathrm{mg} / \mathrm{kg}$ was given for muscle relaxation. Endotracheal intubation was performed by an anesthesiologist. The mean arterial pressure (MAP), heart rate (HR), and the corrected QT (QTc) interval were measured before induction, before laryngoscopy, and immediately after tracheal intubation. Genomic DNA was isolated from the patients' peripheral blood and then evaluated for the $\beta_{1} A R-49$ and $\beta_{1} A R$-389 genes using an allele-specific polymerase chain reaction method.

Results: No differences were found in the baseline values of MAP, HR, and the QTc interval among $\beta_{1} A R-49$ and $\beta_{1} A R-389$, respectively. In the case of $\beta_{1} A R-49$, the QTc interval change immediately after tracheal intubation was significantly greater in Ser/Ser genotypes than in Ser/Gly genotypes. No differences were observed immediately after tracheal intubation in MAP and HR for $\beta_{1} A R-49$ and $\beta_{1} A R-389$.

Conclusions: We found an association between the Ser 49 homozygote gene of $\beta_{1} A R-49$ polymorphism and increased QTc prolongation during endotracheal intubation with sevoflurane anesthesia. Thus, $\beta_{1} A R-49$ polymorphism may be useful in predicting the risk of arrhythmia during endotracheal intubation in patients with long QT syndrome. (Korean J Anesthesiol 2011; 61: 117-121)

Key Words: Betal adrenergic receptor, Endotracheal intubation, Polymorphism.

Received: November 18, 2010. Revised: 1st, January 5, 2011; 2nd, January 10, 2011. Accepted: January 10, 2011.

Corresponding author: Dong Woo Han, M.D., Ph.D., Department of Anaesthesiology and Pain Medicine and Anaesthesia and Pain Research Institute, Gangnam Severance Hospital, Unju-ro 612, Dogok-dong, Gangnam-gu, Seoul 135-720, Korea. Tel: 82-2-2019-2740, Fax: 82-2-34630940, E-mail: hanesth@yuhs.ac

(c) This is an open-access article distributed under the terms of the Creative Commons Attribution Non-Commercial License (http:// creativecommons.org/licenses/by-nc/3.0/), which permits unrestricted non-commercial use, distribution, and reproduction in any medium, provided the original work is properly cited. 


\section{Introduction}

Endotracheal intubation using laryngoscopy increases arterial pressure, heart rate, and the incidence of cardiac arrhythmias, which usually cause little consequence in healthy patients but may be detrimental to patients with cardiovascular diseases [1-3]. The hemodynamic responses to laryngoscopy and tracheal intubation are caused by a catecholamine discharge associated with sympathoadrenal activity. The corrected QT (QTc) interval can also be prolonged during rapid injection of catecholamine, brief stimulation of the sympathetic nervous system, and an imbalance of the cardiac sympathetic tone [4-7].

Stimulation of the sympathetic nervous system, due to exercise or emotional stress, causes activation of cardiac $\beta$-adrenoceptors. Beta1-adrenergic receptor $\left(\beta_{1} A R\right)$ is an important mediator of the sympathetic cascade and regulates numerous physiologic events, including heart rate and contractility. Polymorphisms in the $\beta_{1} A R$ gene can affect responses to drugs in patients with hypertension or heart failure and alter the pathophysiology of specific disease states, where sympathetic activation plays a major role. The $\beta_{1} A R$ gene is localized to chromosome 10 and two common polymorphisms, Ser49Gly and Arg389Gly, were identified in 1999 [8].

The Ser49Gly polymorphism is located in the extracellular amino-terminal region of the receptor and the Gly49 variant correlates with the development of cardiomyopathy and heart failure $[9,10]$. Arg389Gly is located in the intracellular cytoplasmic tail near the seventh transmembrane region of the receptor, which is a putative Gs-protein binding domain. Patients homozygous for the Arg389 allele are at an increased risk for developing hypertension [11]. Given these findings, endogenous catecholamine stimulation of $\beta_{1} A R$ during endotracheal intubation may result in enhanced cardiovascular response in one genotype over another. No study has been made on $\beta_{1} A R$ polymorphism with cardiovascular responses to endotracheal intubation under laryngoscopy.

The aim of the present study is to investigate whether the functionally important Ser49Gly polymorphism and the Arg389Gly polymorphism of the $\beta_{1} A R$ gene have different cardiovascular responses during endotracheal intubation under sevoflurane anesthesia.

\section{Materials and Methods}

After obtaining approval from our Institutional Review Board and receiving written informed consent from the participants, 100 patients (American Society of Anesthesiologists physical status class 1) between the ages of 20 and 50 were enrolled in this study. Patient exclusion criteria were: abnormal serum electrolyte values, a QTc interval duration greater than 440 ms, taking medication affecting QTc interval duration (tricylic antidepressant agents, antidysrhythmics, beta adrenergic antagonists, calcium channel blocking agents), the existence of valvular cardiac disease, and any cardiac rhythm other than sinus rhythm, diabetes mellitus, pregnancy, or obesity.

All study data were collected in the morning (8:00-11:00) to prevent the effects of day-night changes on the QTc interval. Patients received no premedication. After being taken into the operating room, electrocardiogram monitoring, pulse oximetry, non-invasive blood pressure, fraction of inspired oxygen and end-tidal sevoflurane, and carbon dioxide concentration monitoring were begun. Blood pressure was measured with an automatic oscillographic device every 2 minute during the study period. After the monitoring equipment had been attached, the patients were allowed to rest for 5 minutes while lactated Ringer's solution $4 \mathrm{ml} / \mathrm{kg}$ was infused before inducing anesthesia. A standard real-time automated threelead electrocardiogram was continuously recorded using a data acquisition system (PowerLab; AD Instruments, Colorado Springs, CO, USA). The QT interval was measured in lead II from the onset of the QRS complex to the end of the T wave, which was defined as a return to the T-P baseline. When $U$ waves were present, the nadir between the $\mathrm{T}$ and $\mathrm{U}$ waves was regarded as the end of the QT interval. Biphasic T waves were considered to end with the final return to baseline. The values of the QT interval of four successive beats were averaged. The QT interval was corrected using the Fridericia formula: QTc $=\mathrm{QT} / \sqrt[3]{ }(\mathrm{R}-\mathrm{R}$ interval).

Patients underwent slow inhalation induction of anesthesia with a facemask using sevoflurane in $100 \%$ oxygen to avoid the confounding effects of other anesthetic agents. Anesthesia was induced by initially administering $1.0 \%$ sevoflurane and increasing the inspiratory concentration after every fifth breath by $0.5 \%$ until a maximum of $6 \%$ sevoflurane was reached. After induction, the anesthesia was maintained with sevoflurane and ventilation was assisted using a facemask at an end-tidal concentration of $3 \%$ sevoflurane to provide an adequate depth of anesthesia. As spontaneous breathing diminished, patients were manually assisted via the facemask while an exhaled tidal volume of $8 \mathrm{ml} / \mathrm{kg}$ was maintained. The respiratory rate was adjusted to maintain an end-tidal carbon dioxide partial pressure of $35 \mathrm{mmHg}$. Vecuronium $0.15 \mathrm{mg} / \mathrm{kg}$ was given for muscle relaxation at $10 \mathrm{~min}$ after induction with sevoflurane. Laryngoscopy was attempted 5 min after vecuronium injection. Laryngoscopy and tracheal intubation were performed by one anesthesiologist, and then the sevoflurane end-tidal concentration was reduced to $2 \%$. Data for patients with a failed intubation on the first attempt or intubations which took more than $40 \mathrm{sec}$ were also excluded from the analysis. The mean arterial pressure (MAP), heart rate (HR), and QTc interval were 
Table 1. Primer Sets and Tm for the SNaPshot Assay

\begin{tabular}{lll}
\hline & $\beta_{1}$-AR S49G $(\mathrm{rs} 1801252)$ & $\beta_{1}$-AR G389R $(\mathrm{rs} 1801253)$ \\
\hline Forward & GACAGCGCTCGGCTCCT & GAGCAGAAGGCGCTCA \\
Reverse & GTAGCGGAAGGGCGAGGT & GTGGCCCCRACGACATC \\
SNP Primer & GCTGAGACAGCGGCTCGGGGC & TGCGCGCGCAGCAGAGCAGTC \\
Tm $\left({ }^{\circ} \mathrm{C}\right)$ & 60 & 60 \\
\hline
\end{tabular}

Table 2. Baseline Parameters in Patients for $\beta_{1} A R-49$ and $\beta_{1} A R-389$

\begin{tabular}{|c|c|c|c|c|c|c|}
\hline \multirow{2}{*}{ Characteristics } & \multicolumn{2}{|c|}{$\beta_{1}$-AR Ser49Gly genotype } & \multirow{2}{*}{$\mathrm{P}$} & \multicolumn{2}{|c|}{$\beta_{1}$-AR Arg389Gly genotype } & \multirow{2}{*}{$P$} \\
\hline & Ser/Ser & Ser/Gly & & Arg/Arg & Gly allele & \\
\hline $\operatorname{Sex}(M / F)$ & $27 / 41$ & $11 / 12$ & 0.495 & $24 / 35$ & $14 / 18$ & 0.777 \\
\hline Age (yr) & $35.7 \pm 9.3$ & $36.0 \pm 8.7$ & 0.898 & $35.3 \pm 9.7$ & $36.6 \pm 8.1$ & 0.505 \\
\hline Height $(\mathrm{cm})$ & $166.4 \pm 9.0$ & $167.1 \pm 8.0$ & 0.756 & $166.4 \pm 9.1$ & $166.7 \pm 8.1$ & 0.873 \\
\hline Weight (kg) & $63.6 \pm 11.0$ & $66.7 \pm 10.8$ & 0.250 & $64.5 \pm 10.4$ & $63.4 \pm 12.0$ & 0.641 \\
\hline MAP (mmHg) & $91.6 \pm 11.9$ & $89.4 \pm 9.9$ & 0.432 & $92.3 \pm 11.6$ & $88.8 \pm 11.1$ & 0.165 \\
\hline $\mathrm{HR}(\mathrm{bpm})$ & $76.4 \pm 12.1$ & $74.0 \pm 13.9$ & 0.454 & $74.5 \pm 12.4$ & $78.2 \pm 12.7$ & 0.187 \\
\hline QTc (msec) & $368.2 \pm 24.4$ & $373.3 \pm 22.4$ & 0.403 & $370.9 \pm 24.9$ & $366.6 \pm 22.0$ & 0.436 \\
\hline
\end{tabular}

Data are presented as mean \pm SD. Baseline parameters were assessed before anesthesia. MAP: mean arterial pressure, HR: heart rate, QTc: corrected QT.

Table 3. Changes in Arterial Pressure, Heart Rate, and QTc Interval

\begin{tabular}{lrcc}
\hline Study variable & $\mathrm{T}_{0}$ & $\mathrm{~T}_{1}$ & \% change \\
\hline MAP (mmHg) & $91.0 \pm 11.5$ & $106.6 \pm 23.3$ & $18.4 \pm 27.7^{*}$ \\
HR (bpm) & $75.8 \pm 12.6$ & $101.2 \pm 19.9$ & $37.8 \pm 37.8^{*}$ \\
QTc (msec) & $369.5 \pm 23.9$ & $412.9 \pm 28.4$ & $12.0 \pm 7.2^{*}$ \\
\hline
\end{tabular}

Data are presented as mean \pm SD. MAP: mean arterial pressure, HR: heart rate, QTc: corrected QT. $\mathrm{T}_{0}$ : prior to induction of anesthesia, $\mathrm{T}_{1}$ : immediately after laryngoscopy and tracheal intubation, \% change: $\left(\mathrm{T}_{1}-\mathrm{T}_{0}\right) \times 100 / \mathrm{T}_{0}$. $* \mathrm{P}<0.001$ by paired $\mathrm{t}$-test.

measured before induction, before laryngoscopy, and immediately after tracheal intubation.

All patients underwent peripheral blood sampling for isolation of genomic DNA. Samples were stored at $-20^{\circ} \mathrm{C}$ until DNA extraction. Genomic DNA was prepared using a nucleic acid isolation device, QuickGene Mini-80 (FUJIFILM, Tokyo, Japan). The genotyping was screened using a single base primer extension assay using ABI PRISM SNaPShot Multiplex kit (ABI, Foster City, CA, USA) according to the manufacturer's recommendations. Table 1 shows the primer sequences and annealing temperatures used for the SNaPshot assay. The polymerase chain reaction (PCR) was performed on an ABI 9700 ThermalCycler (ABI, Foster City, CA). After amplification, the PCR product was purified using shrimp alkaline phosphatase (SAP) (USB Corporation, Cleveland, OH, USA) and exonuclease I (USB Corporation, Cleveland, OH, USA). One $\mu \mathrm{l}$ of the purified amplification products was added to a SNaPshot Multiplex Ready reaction mixture containing $0.15 \mathrm{pM}$ of genotyping primer for the primer extension reaction. Then, the sequences were analyzed on an ABI Prism 3730xl DNA analyzer (Applied Biosystems, USA). Analysis was carried out using Genemapper software (version 4.0; Applied Biosystems).

Statistical analysis was performed with SPSS 12.0 (SPSS Inc., Chicago, IL, USA). All values were expressed as mean \pm SD. Differences in MAP, HR, and QTc interval were determined using a paired t-test. Comparisons between the two groups were analysed using Student's t-test or a paired t-test where applicable. A $P$ value of $<0.05$ was considered significant.

\section{Results}

Ninety-one of 100 patients completed this study. The nine patients were excluded from the analysis due to failed intubation on the first attempt or delayed intubation which took more than $40 \mathrm{sec}$. Ninety-one patients (38 men and 53 female, age $35.8 \pm 9.1$, weight $64.3 \pm 10.9 \mathrm{~kg}$, and height $166.6 \pm 8.7 \mathrm{~cm}$ ), were enrolled into the study.

The allelic frequencies of the mutant Gly49 and Gly389 were $12.6 \%$ and $19.8 \%$, respectively. Table 2 shows the baseline values of MAP, HR, and the QTc interval of the $\beta_{1} A R-49$ and $\beta_{1} A R-389$ gene polymorphism. No differences were found in the baseline values of MAP, HR, and the QTc interval for $\beta_{1} A R-49$ and $\beta_{1} A R-$ 389 , respectively. Significant increases were detected in MAP, $\mathrm{HR}$, and the QTc interval following laryngoscopy and tracheal intubation (Table 3).

When the percentage change of MAP, HR and the QTc interval was examined by genotype immediate after intubation, only in $\beta_{1} A R-49$, was the change of the QTc interval significantly greater 
Table 4. Percentage Change of Mean Arterial Pressure, Heart Rate, and QTc Interval According to the Genotype of $\beta_{1}$-AR Polymorphisms

\begin{tabular}{|c|c|c|c|c|c|c|}
\hline \multirow{2}{*}{ Characteristics } & \multicolumn{2}{|c|}{$\beta_{1}$-AR Ser49Gly genotype } & \multirow{2}{*}{$\mathrm{P}$} & \multicolumn{2}{|c|}{$\beta_{1}$-AR Arg389Gly genotype } & \multirow{2}{*}{$\mathrm{P}$} \\
\hline & Ser/Ser & Ser/Gly & & Arg/Arg & Gly allele & \\
\hline \% Increase of MAP & $14.7 \pm 28.4$ & $29.9 \pm 22.2$ & 0.067 & $16.6 \pm 26.0$ & $21.6 \pm 30.8$ & 0.886 \\
\hline$\%$ Increase of HR & $33.3 \pm 36.5$ & $51.4 \pm 39.5$ & 0.347 & $39.5 \pm 38.4$ & $34.7 \pm 37.1$ & 0.601 \\
\hline \% Increase of QTc & $13.0 \pm 7.0$ & $9.1 \pm 7.1$ & 0.005 & $12.0 \pm 6.9$ & $12.1 \pm 7.7$ & 0.614 \\
\hline
\end{tabular}

Data are presented as mean \pm SD. MAP: mean arterial pressure, HR: heart rate, QTc: corrected QT.

in Ser/Ser genotypes than Ser/Gly genotypes. No differences were observed immediately after tracheal intubation in the change of MAP and HR for $\beta_{1} A R-49$ and $\beta_{1} A R-389$, respectively (Table 4).

\section{Discussion}

We found that the allelic frequencies of the Gly49 and Gly389 single-nucleotide polymorphism (SNP) were $12.6 \%$ and $19.8 \%$, respectively, which were similar to the $15 \%$ and $27 \%$ found in studies on Caucasians $(\mathrm{P}>0.05)$ [8]. The increase in the QTc interval was greater in Ser/Ser than Ser/Gly for $\beta_{1} A R-49$, whereas no difference in the percentage change of MAP and HR was observed for $\beta_{1} A R-49$ and $\beta_{1} A R-389$.

In the human heart, $\beta_{1} A R$ and $\beta_{2} A R$ coexist, and $\beta_{1} A R$ predominates. $\beta_{1} A R$ actively participates in the regulation of heart rate and contractility in cardiomyocytes. The $\beta_{1} A R$ couples to the Gs-protein thereby elevating the intracellular level of cyclic AMP and causing positive inotropic and chronotropic effects, in vitro as well as in vivo [12].

Several studies have investigated a possible impact of the Ser49Gly and Arg389Gly $\beta_{1} A R$ polymorphism on resting hemodynamics and hypertension, but the results were variable [13-20]. The Gly49 variant demonstrated characteristic features of a constitutively active receptor. In cells expressing the Gly49 $\beta_{1} A R$, basal and agonist-stimulated adenylyl cyclase activity was higher than that of Ser49 $\beta_{1} A R$. The Gly $49 \beta_{1} A R$ was more sensitive to the inhibitory effects of antagonists, such as metoprolol, and displayed increased affinities for the agonist $[13,14]$. However, other studies on the phenotypic effects of the $\beta_{1} A R$ polymorphism have revealed controversial data. The Gly49Gly receptor showed greater long-term agonist-promoted down-regulation than the Ser49Ser receptor and subjects with Gly49Gly had significantly lower resting heart rates than patients carrying the 1 or 2 Ser alleles [15]. In our study, the increase of the QTc interval was greater in Ser/Ser than Ser/ Gly for $\beta_{1} A R-49$, which was consistent with Paavonen's findings showing that patients with the Ser49Ser genotype had a longer QT interval during exercise than patients with other genotypes [16]. Our findings suggest that Ser49 homozygotes are more active and risky alleles than the other variants in the QTc prolongation associated with endotracheal intubation.

Isoprenaline-induced adenylyl cyclase activation was 3-4 times higher in the Arg389 receptor than in the Gly389 receptor [17]. These differences were due to a greater coupling of the Arg389 receptor to the Gs-protein than was found in the Gly389 receptor. Greater inotropic and cyclic AMP responses to catecholamine were reported in Arg389 homozygotes when the dobutamine stress test was performed [18,19]. The Arg389 $\beta_{1} A R$ exhibited greater short-term agonist-promoted desensitization than the Gly389 $\beta_{1} A R$ [20]. However, some studies found no differences in the increase in exercise-induced heart rates and contractility in Arg389- and Gly389 $\beta_{1} A R$ subjects, whereas dobutamine evoked greater increases of heart rate and contractility in Arg389- than in Gly389 $\beta_{1} A R$ subjects [21]. The reason for this discrepancy in cardiac responses to exercise with dobutamine is not completely understood. However, exercise may induce more physiologic responses, which are dependent on the physical fitness of the subjects, while dobutamine infusion may induce more pharmacologic responses [22]. According to our results, no difference in cardiovascular phenotypes immediately after tracheal intubation was found in $\beta_{1} A R$ 389 gene polymorphism. The exact mechanism for this was not clear, but the intubation-induced cardiovascular response was more similar to exercise-induced cardiovascular change than the change due to catecholamine infusion. Our results suggest that the Arg389Gly polymorphism of the $\beta_{1} A R$ made little or no contribution to the difference in cardiovascular changes from endotracheal intubation during sevoflurane anesthesia.

Our study has a limitation in that endotracheal intubation was not the only factor that influenced the QTc interval. We cannot rule out the effect of sevoflurane on the QTc interval prolongation during endotracheal intubation, although no differences in the QTc interval before endotracheal intubation were found for Ser49Gly and Gly389Arg polymorphism (data not shown). Most anesthetic agents, including sevoflurane, prolong the QTc interval $[23,24]$, which was consistent with the results of this study (data not shown). In this study, inhalation induction with sevoflurane was performed without premedication or intravenous induction agents to avoid the complicating effect of other anesthetic drugs on the QTc interval. This is because the effect of some anesthetics on the 
QTc interval remains controversial. To facilitate endotracheal intubation, vecuronium was administered, because it lacks an autonomic effect and causes no significant change in the QTc interval [25].

In conclusion, we found an association between the Ser49 homozygote gene of $\beta_{1} A R-49$ polymorphism and increased QTc prolongation during endotracheal intubation with sevoflurane anesthesia. Thus, $\beta_{1} A R-49$ polymorphism may be useful for predicting the risk of arrhythmia during endotracheal intubation in patients with congenital or acquired long QT syndrome.

\section{Acknowledgements}

This study was supported by a faculty research grant of Yonsei University College of Medicine for 2007 (6-2007-0186).

\section{References}

1. King BD, Harris LC Jr, Greifenstein FE, Elder JD Jr, Dripps RD. Reflex circulatory responses to direct laryngoscopy and tracheal intubation performed during general anesthesia. Anesthesiology 1951; 12: 556-66.

2. Forbes AM, Dally FG. Acute hypertension during induction of anaesthesia and endotracheal intubation in normotensive man. $\mathrm{Br}$ J Anaesth 1970; 42: 618-24.

3. Korpinen R, Saarnivaara L, Siren K. QT interval of the ECG, heart rate and arterial pressure during anaesthetic induction: comparative effects of alfentanil and esmolol. Acta Anaesthesiol Scand 1995; 39: 809-13.

4. Abildskov JA. Adrenergic effects of the QT interval of the electrocardiogram. Am Heart J 1976; 92: 210-6.

5. Moss AJ, McDonald J. Unilateral cervicothoracic sympathetic ganglionectomy for the treatment of long QT interval syndrome. N Engl J Med 1971; 285: 903-4.

6. Tomori Z, Widdicombe JG. Muscular, bronchomotor and cardiovascular reflexes elicited by mechanical stimulation of the respiratory tract. J Physiol 1969; 200: 25-49.

7. Magnano AR, Talathoti N, Hallur R, Bloomfield DM, Garan H. Sympathomimetic infusion and cardiac repolarization: the normative effects of epinephrine and isoproterenol in healthy subjects. J Cardiovasc Electrophysiol 2006; 17: 983-9.

8. Maqbool A, Hall AS, Ball SG, Balmforth AJ. Common polymorphisms of betal-adrenoceptor: identification and rapid screening assay. Lancet 1999; 353: 897.

9. Podlowski S, Wenzel K, Luther HP, Müller J, Bramlage P, Baumann $\mathrm{G}$, et al. Betal-adrenoceptor gene variations: a role in idiopathic dilated cardiomyopathy? J Mol Med 2000; 78: 87-93.

10. Börjesson M, Magnusson Y, Hjalmarson A, Andersson B. A novel polymorphism in the gene coding for the beta(1)-adrenergic receptor associated with survival in patients with heart failure. Eur
Heart J 2000; 21: 1853-8.

11. Bengtsson K, Melander O, Orho-Melander M, Lindblad U, Ranstam J, Råstam L, et al. Polymorphism in the beta(1)-adrenergic receptor gene and hypertension. Circulation. 2001; 104: 187-90.

12. Brodde OE, Michel MC. Adrenergic and muscarinic receptors in the human heart. Pharmacol Rev 1999; 51: 651-90.

13. Levin MC, Marullo S, Muntaner O, Andersson B, Magnusson Y. The myocardium-protective Gly- 49 variant of the beta 1-adrenergic receptor exhibits constitutive activity and increased desensitization and down-regulation. J Biol Chem 2002; 277: 30429-35.

14. Rathz DA, Brown KM, Kramer LA, Liggett SB. Amino acid 49 polymorphisms of the human beta1-adrenergic receptor affect agonist-promoted trafficking. J Cardiovasc Pharmacol 2002; 39: $155-60$.

15. Ranade K, Jorgenson E, Sheu WH, Pei D, Hsiung CA, Chiang FT, et al. A polymorphism in the betal adrenergic receptor is associated with resting heart rate. Am J Hum Genet 2002; 70: 935-42.

16. Paavonen KJ, Swan H, Piippo K, Laitinen P, Fodstad H, Sarna S, et al. Beta1-adrenergic receptor polymorphisms, QTc interval and occurrence of symptoms in type 1 of long QT syndrome. Int J Cardiol 2007; 118: 197-202.

17. Mason DA, Moore JD, Green SA, Liggett SB. A gain-of-function polymorphism in a G-protein coupling domain of the human betal-adrenergic receptor. J Biol Chem 1999; 274: 12670-4.

18. La Rosée K, Huntgeburth M, Rosenkranz S, Böhm M, Schnabel P. The Arg389Gly beta1-adrenoceptor gene polymorphism determines contractile response to catecholamines. Pharmacogenetics 2004; 14: 711-6.

19. Sandilands AJ, O'Shaughnessy KM, Brown MJ. Greater inotropic and cyclic AMP responses evoked by noradrenaline through Arg389 beta 1-adrenoceptors versus Gly389 beta 1-adrenoceptors in isolated human atrial myocardium. Br J Pharmacol 2003; 138: 38692.

20. Rathz DA, Gregory KN, Fang Y, Brown KM, Liggett SB. Hierarchy of polymorphic variation and desensitization permutations relative to beta 1- and beta 2-adrenergic receptor signaling. J Biol Chem 2003; 278: 10784-9.

21. Leineweber K, Büscher R, Bruck H, Brodde OE. Beta-adrenoceptor polymorphisms. Naunyn Schmiedebergs Arch Pharmacol 2004; 369: 1-22.

22. Bruck H, Leineweber K, Temme T, Weber M, Heusch G, Philipp T, et al. The Arg389Gly betal-adrenoceptor polymorphism and catecholamine effects on plasma-renin activity. J Am Coll Cardiol 2005; 46: 2111-5.

23. Chae JE, Kim CH, Min KT, Park WK. Electrophysiologic mechanisms of sevoflurane on prolongation of the QT interval: $\mathrm{K}^{+}$currents in rat ventricular myocytes. Korean J Anesthesiol 2006; 50: 454-62.

24. Kuenszberg E, Loeckinger A, Kleinsasser A, Lindner KH, Puehringer F, Hoermann C. Sevoflurane progressively prolongs the QT interval in unpremedicated female adults. Eur J Anaesthesiol 2000; 17: 662-4.

25. Wisely NA, Shipton EA. Long QT syndrome and anaesthesia. Eur J Anaesthesiol 2002; 19: 853-9. 